\title{
Balance and motion coordination parameters can be improved in patients with type 2 diabetes with physical balance training - non-randomized controlled trial
}

Artur Stolarczyk

Medical University of Warsaw: Warszawski Uniwersytet Medyczny

Igor Jarzemski

Medical University of Warsaw

Bartosz M. Maciąg ( $\square$ bmaciag@wum.edu.pl)

Warszawski Uniwersytet Medyczny https://orcid.org/0000-0002-0311-3735

Magda Stolarczyk

Medical Universty of Warsaw

\section{Research article}

Keywords: Diabetes mellitus, Balance, Fall risk, Physical training, Coordination

Posted Date: November 4th, 2020

DOI: https://doi.org/10.21203/rs.3.rs-50752/v1

License: (c) (1) This work is licensed under a Creative Commons Attribution 4.0 International License. Read Full License 


\section{Abstract}

\section{Background}

Diabetes mellitus type II (DMII) causes many complications, including retinopathy and peripheral neuropathy. These complications are well understood and believed to contribute to gait instability and increase the risk of falls. Poor balance control and increased falling risk have also been reported in people with diabetic peripheral neuropathy (DPN).

Patients with DPN are at an increased risk of falling due to the decreased proprioceptive feedbacks. Effective balance training should improve instabilities of postural control in patients with DPN. For this purpose, evaluations and balance training was designed.

\section{Methods}

The goal of our study was to establish values for proprioception, balance, muscle coordination and strength in patients with DMII and analyze whether biofeedback balance training using the Biodex Balance System can improve those parameters. To predict fall risk parameters such as overall stability index, the index of frontal-posterior and medial-lateral stability measurements were obtained. 37 patients with diagnosed type II diabetes mellitus were recruited to this study. Their results were compared with control group consisting of 41 healthy participants who were homogenic to the study group in terms of age and body mass index (BMI).

\section{Results}

Statistically significantly worse results for all three stability indexes in patients with diabetes compared to healthy subjects. For both the overall stability index and the index of frontal-posterior and medial-lateral stability $(p<0.05)$. There was statistically significant improvement in static balance with visual control in study group who received training with biological feedback. A statistically significant improvement was observed for all 3 stability indices ( $<<0.05$ ). There was a statistically significant increase in the risk of falling in people with diabetes compared to healthy individuals. Statistically significant decrease in the risk of falling was observed in the study group who had undergone training with biofeedback $(p<0.05)$.

\section{Conclusions}

This study found decreased balance and motor coordination and an increasing risk of falling in patient with type II diabetes that improved after training with biofeedback. Furthermore we established an age-dependent deprivation of static balance and an increased risk of falling as a result of increasing BMI.

\section{Trial registration}

This study was registered on ClinicalTrials.gov. Registration number: NCT04484480

\section{Background}

Due to the sociological, occupational changes all around the world it is predicted that by the beginning of 2030, number of cases of diabetes mellitus type II (DMII) on 100000 people will grow from 6059 up to 7079. (1) There are studies proving that cardiovascular complications related to the DMII are responsible for 4 millions of deaths annually. (2) The newest epidemiological data suggest that growing number of DMIl cases is no longer a problem in developed countries but also affects developing ones. In research performed in Uganda investigators reported that as many as $22.8 \%$ of population between 45 and 80 years of age might be affected with this disease. As potential risk factors, well proved in the literature authors reported alcoholism, nicotinism, high bodymass index (BMI) and family history. (3)

Diabetes mellitus may cause several different complications during course of the disease. One of the most common is peripheral neuropathy (DPN) causing damage to the peripheral sensory and motor nerves even in mild to moderate course of the disease. (4). It is well proved in the literature, that diabetes mellitus influences negatively function of peripheral nervous system by damaging sensory fibers, and the factors having the biggest influence are age and male sex. (5)

A high risk of falls has been reported in the diabetic population, with an overall incidence of 1.25 falls/person-year (6). It was proven that short-period strength and balance exercises do not improve diabetic patients quality of life However they have positive influence on the functional outcome of those people. $(7,8)$

Influence of DMII on motor system is not limited only to the peripheral nervous system. It also affects structures of cerebrum, what leads to changes in projection tracts. In cerebellum it affects the vermis and parts of lobes responsible for receiving impulses from the spinal cord and controlling proximal parts of muscles, which are crucial for movement coordination during gait. Disorders caused by DMII in basal nuclei result in lengthening muscle response time and slower gait velocity (9).

Pharmacological and dietary interventions, together with physical activity are considered the cornerstones of proper DMII management. (10). In addition to the beneficial effects of exercise interventions on glycemic control and lowering the cardiovascular risk factors associated with type 2 diabetes, physical exercise is an effective intervention to improve muscle strength, power output, cardiovascular function and functional capacity in elderly diabetic patients (11, 12). In the elderly with severe functional decline, multicomponent exercise programs composed of resistance, endurance, balance and gait retraining should be employed to increase functional capacity and quality of life and to avoid disability and falls (13).

\section{Methods}


This study is reported in accordance with the Preferred Reporting Items for Consolidated Standards Of Reporting Trials (CONSORT) statement.

The aim of the study was to evaluate balance and motor coordination parameters in patients treated for type 2 diabetes who received biofeedback-equivalent training using the Biodex dynamometric platform.

The hypothesis was that there was no improvement in the above-mentioned parameters in patients with type II diabetes in patients subjected to feedback based training using the Biodex platform.

There were 77 participants included in this study. The study group consisted of 37 patients diagnosed and treated with type II diabetes. 41 patients were recruited to the control group. There were 18 men and 19 women in the study group, mean age $73.22(\mathrm{SD}=7.57)$. The average $\mathrm{BMI}$ was $29.5(\mathrm{SD}=4.5)$, with 5 people having normal body mass (BMI $=18.9-24.9)$, 17 being overweight $(\mathrm{BMI}=25-29.9), 12$ with obesity in the first degree $(\mathrm{BMI}=30-34.9), 1$ person with second degree obesity $(\mathrm{BMI}=35-39.9)$ and 2 people with third degree (BMI > 40). All subjects were the patients of the Department of Internal Medicine and Diabetology of the Medical University of Warsaw, who underwent standard diabetes control visit on January 2020.

The control group included 41 people with a mean age of $74.1(\mathrm{SD}=4.33)$, including 24 women and 17 men. The mean $\mathrm{BMI}$ was $26.88(\mathrm{SD}=2.4)$, including 7 people with normal weight, 30 with overweight and 4 with grade I obesity (Table 1).

Table 1

Descriptive statistics - study group (B) and control group (K).

\begin{tabular}{|c|c|c|c|c|c|c|c|c|c|c|c|c|c|c|}
\hline \multirow[t]{4}{*}{ Variable } & \multicolumn{14}{|c|}{ Descriptive statistics for study group and control group } \\
\hline & $\mathbf{N}$ & Average & Min & Max & $S D$ & $\mathrm{Cl}$ & $\mathrm{Cl}$ & $N$ & Average & Min & Max & $S D$ & $\mathrm{Cl}$ & $\mathrm{Cl}$, \\
\hline & & & & & & $-95,00 \%$ & $95,00 \%$ & & & & & & $-95,00 \%$ & - \\
\hline & & & & & & & & & & & & & & $95,00 \%$ \\
\hline Height [m] & 37 & 1,68 & 1,48 & 2 & 0,12 & 0,1 & 0,16 & 41 & 1,69 & 1,53 & 1,82 & 0,09 & 0,07 & 0,11 \\
\hline Weight [kg] & 37 & 84,35 & 42 & 133 & 18,65 & 15,17 & 24,23 & 41 & 76,71 & 53 & 99 & 11,82 & 9,7 & 15,12 \\
\hline BMI & 37 & 29,54 & 19,17 & 41 & 4,54 & 3,69 & 5,9 & 41 & 26,88 & 20,76 & 30,81 & 2,4 & 1,97 & 3,07 \\
\hline
\end{tabular}

Inclusion criteria:

- willingness to participate in the study

- age over 65

- diagnosed type 2 diabetes, subjected to pharmacological treatment (study group)

- no type 2 diabetes (control group)

Exclusion criteria:

- unwillingness to participate in the study

- age below 65 years

- surgical intervention in the lower limbs or spine during the last 6 months

- symptoms of osteoarthritis or pain of another origin around the lower limbs or spine

- rheumatic diseases (eg Rheumatoid arthritis, ankylosing spondylitis)

- diagnosed neuromuscular disease

- strongly manifested imbalances due to impairment of central or peripheral nervous system

- neurological disorders with dizziness, nystagmus, dermatologic or profound (cerebrospinal syndrome, dizziness, multiple sclerosis, Parkinson's disease, etc.).

All participants in the study group were subjected to a 3-month intention-to-treat balance training. Measurements were made right before and immediately after training. In the control group, the tests were performed once to determine baseline parameters for proprioception and balance for a given age group. To avoid risk of bias information of potential DMII was blinded for the assessor.

Intervention

The subjects were subjected to proprioception, balance and motor coordination training using the dynamic platform - Biodex Balance System. The platform software includes ready-to-use exercise protocols that are simple games involving moving the center of gravity of the body in a specific way in both static and dynamic settings. These games are based on a biofeedback mechanism and require conscious adjusting the subjects body position according to a spot on the monitor that corresponds to the subjects own center of gravity. 
Training sessions were held daily for 3 months, excluding the weekends. The duration of a single training session was 30 minutes. The difficulty of training was chosen individually for the needs of the patient. Initially, the training was done on a stable basis. As the patient trained, the difficulty of the exercise increased, adding exercises on an unstable substrate. In addition, the task required a more precise control of the center of gravity.

Evaluation of balance and motion coordination parameters was performed using the Biodex Balance System platform, which makes it possible to evaluate the aforementioned parameters in statics and dynamics. Each patient performed three tests: a biofeedback posture test, with closed eyes and a fall risk test. The posture stability test consisted in maintaining the center of gravity at one point with a stable substrate. Three stability measures have been identified based on three 20-second balance attempts: General Stability Index (GSI), FPI (Frontal-Posterior Stability Index) and MLI (Medial-Lateral Stability Index). The smaller the value of the indicators, the better the test score. The test was performed with opened and closed eyes.

Fall risk test

In the fall risk (RF) test using the Biodex platform, the test subject was told to maintain the center of gravity on an unstable substrate in three 20 -second trials. The lower the values of the fall index were, the better the result.

Methods of statistical analysis

Statistica 13.1 was used for statistical analysis of the obtained results. As the variables did not have a normal distribution, the non-parametric Mann-Whitney test was used to compare the results of the control group with the study group. In order to compare the results within the group before and after the training, non-parametric Wilcoxon pairs were used. The threshold of statistical significance was assumed to be 0.05 . In addition, the upper and lower limits of the $95 \%$ confidence interval for the mean difference were determined. A correlation analysis was also performed to examine the linear relationship between the variables. For each correlation the strength of the relationship was determined: weak, moderate or strong. Correlation coefficient values from 0 to 0.3 were described as a weak correlation, values from 0.3 to 0.5 as moderate and values from 0.5 to 1 as strong. As the variables had no normal distribution, the correlations were calculated on the basis of the nonparametric Spearman coefficient.

\section{Results}

No participant was lost to the follow-up.

Stability test of posture with biofeedback

The results of the assessment of balance and movement coordination parameters using the postural stability test under eye control are presented in Table 2 .

Tab.2. Results of biofeedback posture test for study group (B) and control (K).

\begin{tabular}{|c|c|c|c|c|c|c|c|c|c|c|c|c|c|c|c|c|c|}
\hline \multirow[t]{4}{*}{ Variable } & \multicolumn{17}{|c|}{ Descriptive statistic for biofeedback posture test } \\
\hline & \multicolumn{11}{|c|}{ Study group (B) } & \multicolumn{6}{|c|}{ Control group (K) } \\
\hline & \multirow[t]{2}{*}{$\mathrm{N}$} & \multicolumn{2}{|c|}{ Average } & \multicolumn{2}{|l|}{ Median } & \multicolumn{2}{|l|}{$\mathrm{SD}$} & \multicolumn{2}{|c|}{$\mathrm{Cl}-95.00 \%$} & \multicolumn{2}{|c|}{$\mathrm{Cl}-95.00 \%$} & \multirow[t]{2}{*}{$\mathrm{N}$} & \multirow[t]{2}{*}{ Average } & \multirow[t]{2}{*}{ Median } & \multirow[t]{2}{*}{ SD } & \multirow{2}{*}{$\begin{array}{l}\mathrm{Cl} \\
-95.00 \%\end{array}$} & \multirow{2}{*}{$\begin{array}{l}\mathrm{Cl} \\
9 !\end{array}$} \\
\hline & & before & after & before & after & before & after & before & after & before & after & & & & & & \\
\hline GSI & 37 & 2,79 & 1,26 & 2,7 & 1,2 & 0,5 & 0,34 & 0,41 & 0,28 & 0,65 & 0,44 & 41 & 1,1 & 1 & 0,25 & 0,2 & 0 , \\
\hline FPI & 37 & 1,66 & 0,77 & 1,5 & 0,7 & 0,57 & 0,36 & 0,46 & 0,29 & 0,74 & 0,47 & 41 & 0,7 & 0,7 & 0,21 & 0,17 & 0 \\
\hline MLI & 37 & 0,88 & 0,54 & 0,8 & 0,5 & 0,36 & 0,19 & 0,3 & 0,15 & 0,47 & 0,24 & 41 & 0,52 & 0,5 & 0,15 & 0,11 & 0 , \\
\hline
\end{tabular}

Statistical analysis using the Mann-Whitney $\mathrm{U}$ test showed statistically significantly worse results for all three stability indexes in patients with diabetes compared to healthy subjects. For both the overall stability index and the index of frontal-posterior and medial-lateral stability, the p-value was less than 0.05 (Fig. 1, 2, 3).

Testing Wilcoxon couples showed statistically significant improvement in static balance with visual control in subjects with type II diabetes (study group) who received training with biological feedback. A statistically significant improvement was observed for all 3 stability indices, $p<0.05$ (Figs. 4, 5, 6).

Posture stability test with closed eyes

In Table 3. the descriptive statistics for the pre- and post-training group and descriptive statistics for the control group were presented.

Tab. 3. Results of test of posture stability with closed eyes for the study group (B) and control (K). 


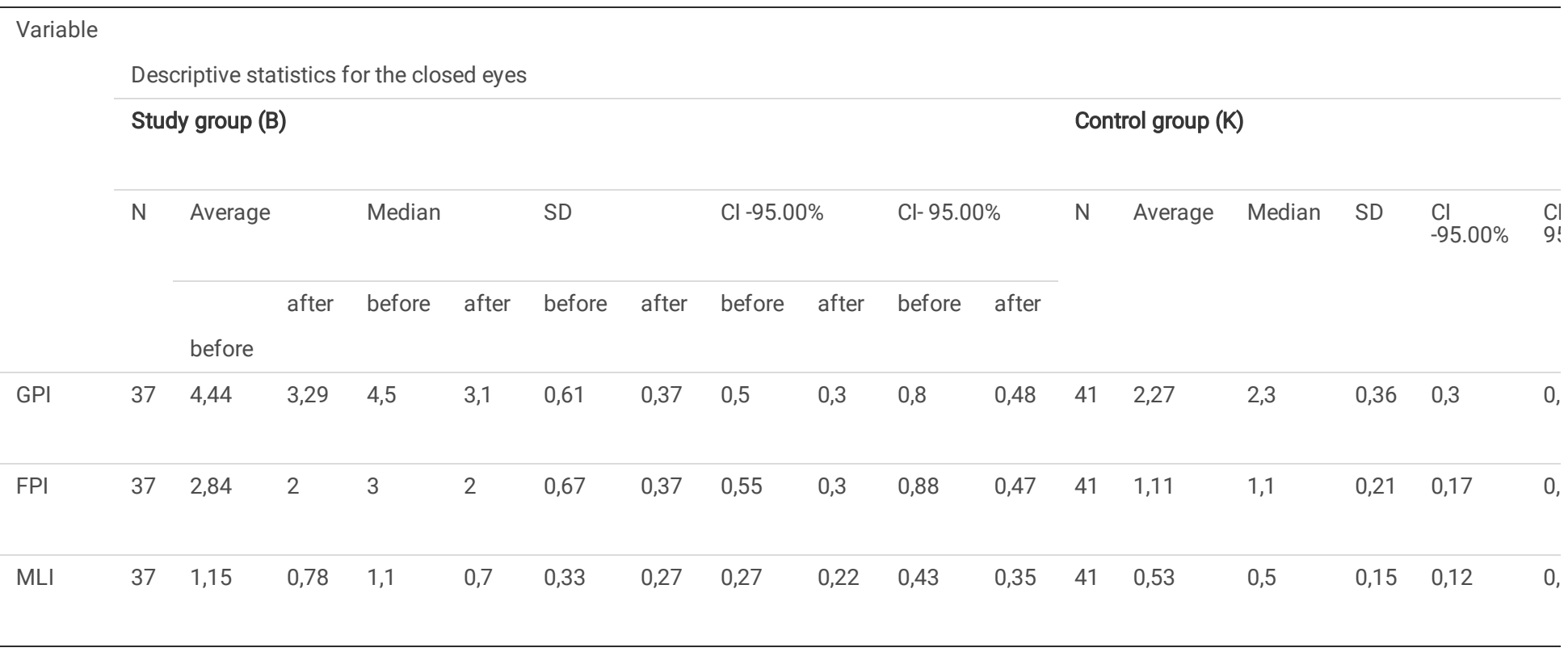

Analysis of the results showed statistically significant disturbances in the parameters of balance and motor coordination in group B patients in relation to group K. Furthermore statistically significant differences in the overall anterior, posterior and medial-lateral stability index $(p<0,05)$. The results are shown in Figs. 7, 8, 9.

Analysis of the results obtained from the study group before and after 3 months of training showed a statistically significant improvement $(p<0.05)$ for all three stability indicators (Figs. 10, 11, 12).

Fall risk test

Table 4. represents the statistical analysis for two groups of participants for a fall risk test (RF), which consisted of maintaining the center of gravity at one point on an unstable substrate.

Tab. 4. Statistics for the fall risk test (RF) for the study (B) and control (K) groups.

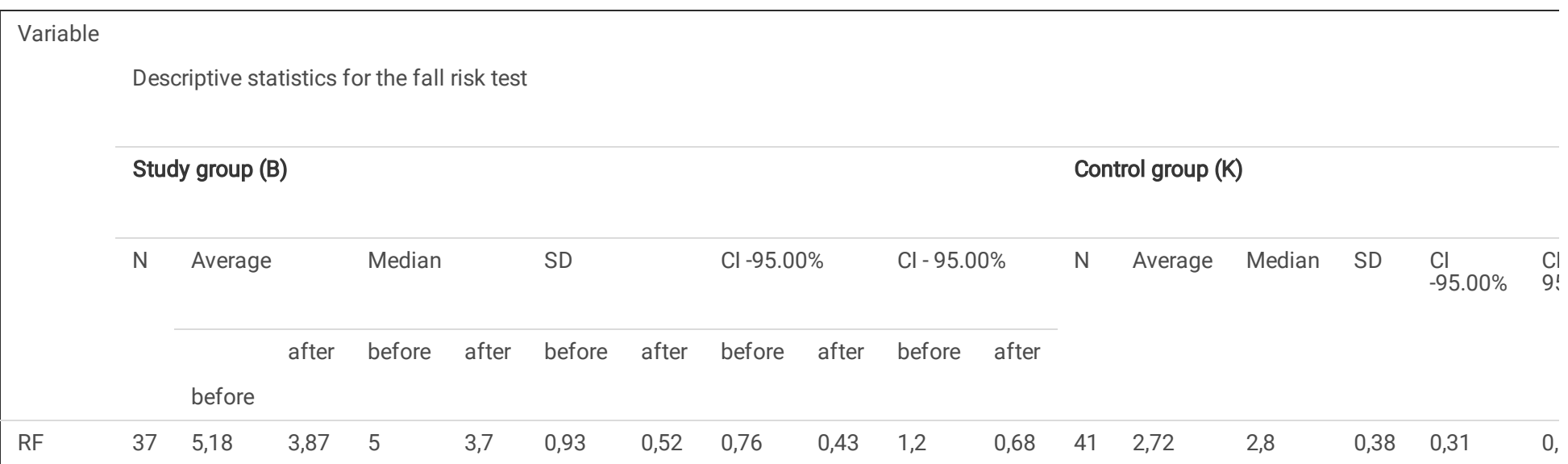

The Mann-Whitney U test showed a statistically significant increase in the risk of falling in people with diabetes compared to healthy individuals (Figs. 13,14). Statistically significant decrease in the risk of falling was observed in the study group who had undergone training with biofeedback $(p<0.05)$.

Correlations

In Table 5. Spearman rank correlation results are shown for the study group prior to the training session. Significant correlations were found, where the significance factor $p$ was less than 0.05 . There was a correlation between the age of patients and the values of general and anterior-posterior stability index during the postural stability test. With the increasing age, the value of GPI, FPI and MLI index values increased during post-biofeedback posture testing. It was observed that with the increase in BMI, the risk of falling in people with diabetes increased.

Tab.5. Spearman rank correlations $(p<0.05)$ for the study group prior to the training session. 


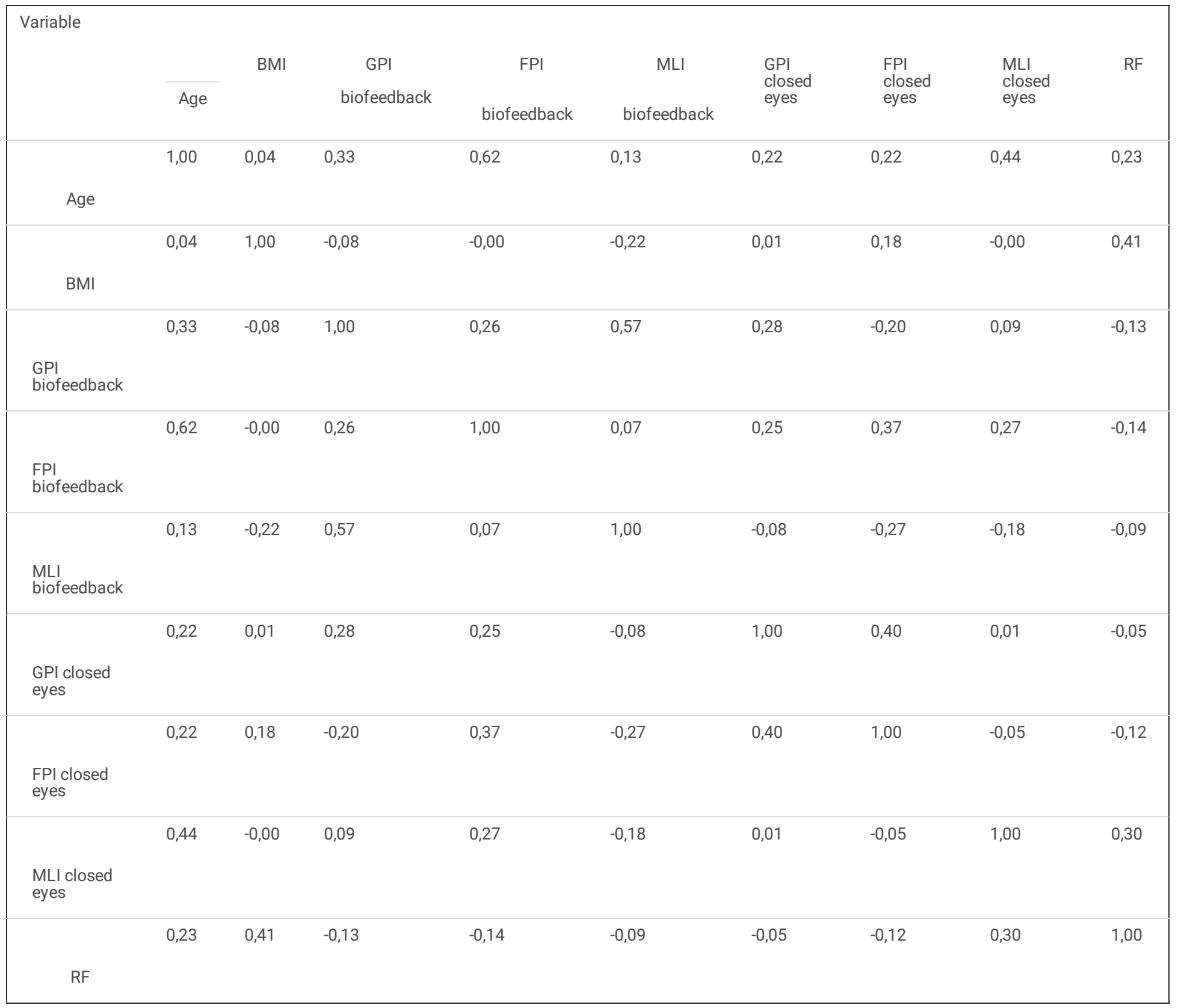

The assessment of the relationship between individual characteristics of diabetic patients subjected to balance training with the help of the Biodex platform is presented in Table 6. It was observed that, with increasing age, balance parameters, in a static setting with opened and closed eyes, and the mean muscle strength, for both knee flexors and extensors were decreased. Analysis showed that, with the deterioration of static balance during biofeedback testing, the strength of the tested muscle groups decreased. Patients with greater BMI showed an increased risk of falling.

Tab.6. Spearman rank correlations $(p<0.05)$ for the study group after the training session 


\begin{tabular}{|c|c|c|c|c|c|c|c|c|c|}
\hline Variable & Age & BMI & $\begin{array}{l}\text { GPI } \\
\text { biofeedback } \\
\text { after }\end{array}$ & $\begin{array}{l}\text { FPI } \\
\text { biofeedback } \\
\text { after }\end{array}$ & $\begin{array}{l}\text { MLI } \\
\text { biofeedback } \\
\text { after }\end{array}$ & $\begin{array}{l}\text { GPI closed } \\
\text { eyes after }\end{array}$ & $\begin{array}{c}\text { FPI } \\
\text { closed } \\
\text { eyes } \\
\text { after }\end{array}$ & $\begin{array}{l}\text { MLI } \\
\text { closed } \\
\text { eyes } \\
\text { after }\end{array}$ & $\begin{array}{l}\mathrm{RF} \\
\text { after }\end{array}$ \\
\hline & 1,00 & 0,04 & 0,52 & 0,57 & 0,73 & 0,34 & 0,09 & 0,49 & 0,26 \\
\hline \multicolumn{10}{|l|}{ Age } \\
\hline & 0,04 & 1,00 & $-0,16$ & $-0,02$ & $-0,05$ & 0,01 & $-0,02$ & 0,03 & 0,44 \\
\hline \multicolumn{10}{|l|}{ BMI } \\
\hline & 0,52 & $-0,16$ & 1,00 & 0,59 & 0,39 & 0,15 & 0,01 & 0,24 & 0,11 \\
\hline & 0,57 & $-0,02$ & 0,59 & 1,00 & 0,57 & 0,11 & 0,06 & 0,30 & 0,04 \\
\hline & 0,73 & $-0,05$ & 0,39 & 0,57 & 1,00 & 0,21 & 0,04 & 0,42 & 0,23 \\
\hline \multicolumn{10}{|l|}{$\begin{array}{l}\text { MLI } \\
\text { biofeedback } \\
\text { after }\end{array}$} \\
\hline & 0,34 & 0,01 & 0,15 & 0,11 & 0,21 & 1,00 & 0,30 & $-0,03$ & $-0,05$ \\
\hline \multicolumn{10}{|l|}{$\begin{array}{l}\text { OWS closed } \\
\text { eyes after }\end{array}$} \\
\hline & 0,09 & $-0,02$ & 0,01 & 0,06 & 0,04 & 0,30 & 1,00 & $-0,28$ & 0,15 \\
\hline \multicolumn{10}{|l|}{$\begin{array}{l}\text { FPI closed } \\
\text { eyes after }\end{array}$} \\
\hline & 0,49 & 0,03 & 0,24 & 0,30 & 0,42 & $-0,03$ & $-0,28$ & 1,00 & 0,07 \\
\hline \multicolumn{10}{|l|}{$\begin{array}{l}\text { MLI closed } \\
\text { eyes after }\end{array}$} \\
\hline & 0,26 & 0,44 & 0,11 & 0,04 & 0,23 & $-0,05$ & 0,15 & 0,07 & 1,00 \\
\hline RF after & & & & & & & & & \\
\hline
\end{tabular}

\section{Discussion}

In diabetic patients a multicomponent exercise program, especially focused on balance exercises and gait retraining, may be an effective intervention to reduce the risk of falling adding to the improvement of functional capacity and quality of life in these patients.

There were several studies analyzing body movement and biomechanics in patients with DPN. In comparison to healthy subjects it is characterized by higher body swing during standing (up to $66 \%$ more), larger range of sway in the anterior-posterior and medial-lateral directions and a higher sway speed during gait. (14-17). However, more significant differences were observed when subjects were asked to perform postural stability test with eyes closed. It was explained as vision compensation of sensory deficits. Several authors underlined the significant influence of slower gait, greater stride variability, longer duration of DMII on higher risk of falls. $(10,18,19)$.

Besides, adults older than 70 years of age and comorbid DM have higher risk of sustaining more severe and potentially more demanding injuries and fractures after falls (20)

Both elderly men and elderly women with diabetes have a higher risk of fractures than adults without diabetes, despite similar bone mineral densities (21). This bone quality loss may be due to more severe glycosylation of amino protein groups in bone tissue, compared to other tissues, as the effect of diabetes (22). This situation increases the risk of fractures by $64 \%$ in people with diabetes compared with people who are healthy (23). It was shown that in people who 
were more than 65 years old and had diabetes, $30.6 \%$ fell recurrently, whereas $19.4 \%$ of people without diabetes had recurrent falls. Recurrent falls were defined as at least 2 falls within a 6 month period (24).

The roles of aerobic exercise, resistance training and a combination of these exercises have been studied thoroughly, but outcomes differ, even though similar exercises were performed. Morrison et al. and Read et al. concluded that these interventions improve glycemic control, overall physical function, balance and gait speed in people with diabetes $(25,26)$. However Kruse et al stated there was no improvement in balance after a 12-month training program that included balance training exercises (27). The explanation for this discrepancy could be the difference in the frequency and the mode of delivery of the training program. Kruse et al. analyzed participants undergoing balance training during 11 weeks. After this initial training period, patients received regular phone calls encouraging them to continue the exercise program (27). Allet et al. prescribed training 2 times per week for 12 weeks, for 60 minutes per session, in a physical therapy clinic (28).

This study showed that balance training improves postural control and clinical measures of balance. It is believed that number and quality of diabetic complications, accompanying intensive balance training affects outcomes.

There are few studies in which balance training programs were effectively used to improve balance and function in people with type 2 diabetes. Given the likelihood that some patients will have visual impairment from retinopathy furthermore affecting their balance capabilities, these type of studies have a special relevance for the diabetic population in establishing falling prevention programs and early treatment protocols.

\title{
Conclusions
}

1. In patients with type II diabetes, we can observe disorders of balance and motor coordination and an increased risk of falling, compared to healthy people in similar age groups.

2. Equivalent training with biofeedback improves balance and motor coordination and reduces the risk of falling in people treated for type II diabetes.

3. As the age of diabetic patients increases, the values of static balance with vision control worsens, both before and after training sessions using the Biodex Balance System.

4. With increasing BMI, the risk of falling of type II diabetic patients was increased both before and after biofeedback training.

\section{Abbreviations}

\author{
DMII - Diabetes Mellitus type II \\ DPN - Diabetic Peripheral Neuropathy \\ BMI - Body Mass Index \\ GSI - General Stability Index \\ FPI - Frontal-Posterior Stability Index \\ MLI - Medial-Lateral Stability Index \\ RF - Fall Risk
}

\section{Declarations}

\section{Ethics approval and consent to participate}

Institutional review board approval required for this study was obtained - Bioethical Committee of Medical University of Warsaw, number of approval: AKBE/56/17. Written consent statement approved by the Committee was obtained from every participant.

\section{Consent for publication}

Not applicable

\section{Availability of data and materials}

The datasets used and/or analyzed during the current study will be available from the corresponding author on reasonable request.

\section{Competing interests}

None declared. 


\section{Funding}

The authors have not declared a specific grant for this research from any funding agency in the public, commercial or not-for-profit sectors.

\section{Authors' contributions}

AS is the first BM is the corresponding author; MS, IJ and AS conceived and designed the study, MS, IJ acquired data; AS, MS, IJ analyzed and interpret data; BM, MS, AS drafted the initial and final manuscripts, all authors performed critical revisions of the manuscript and approved the final version of the manuscript.

\section{Acknowledgements}

Not applicable

\section{References}

1. Khan, M. A. B., Hashim, M. J., King, J. K., Govender, R. D., Mustafa, H., \& Al Kaabi, J. (2019). Epidemiology of Type 2 Diabetes - Global Burden of Disease and Forecasted Trends. Journal of Epidemiology and Global Health, 10(1), 107. doi.org/10.2991/jegh.k.191028.00

2. Wang, C.-Y., Neil, D. L., \& Home, P. (2018). 2020 vision - An overview of prospects for diabetes management and prevention in the next decade. Diabetes Research and Clinical Practice, 143, 101-112. doi.org/10.1016/j.diabres.2018.06.007

3. Asiimwe, D., Mauti, G. O., \& Kiconco, R. (2020). Prevalence and Risk Factors Associated with Type 2 Diabetes in Elderly Patients Aged 45-80 Years at Kanungu District. Journal of Diabetes Research, 2020, 1-5. doi.org/10.1155/2020/5152146

4. Gutierrez EM, Helber MD, Dealva D, Ashton-Miller JA, Richardson JK. Mild diabetic neuropathy affect ankle motor function. Clinical Biomechanics. 2001; 16:522-528.

5. Rinkel, W. D., van Nieuwkasteele, S., Castro Cabezas, M., van Neck, J. W., Birnie, E., \& Coert, J. H. (2019). Balance, risk of falls, risk factors and fall-related costs in individuals with diabetes. Diabetes Research and Clinical Practice, 158, 107930. doi.org/10.1016/j.diabres.2019.107930

6. Wallace C, Reiber GE, LeMaster J, Smith DG, Sullivan K, Hayes S, et al. Incidence of falls, risk factors for falls and fall-related fractures in individuals with diabetes and a prior foot ulcer. Diabetes Care. 2002; 25:1983-1986.

7. Venkataraman, K., Tai, B. C., Khoo, E. Y. H., Tavintharan, S., Chandran, K., Hwang, S. W., Phua, M. S. L. A., Wee, H. L., Koh, G. C. H., \& Tai, E. S. (2019). Shortterm strength and balance training does not improve quality of life but improves functional status in individuals with diabetic peripheral neuropathy: a randomised controlled trial. Diabetologia, 62(12), 2200-2210. https://doi.org/10.1007/s00125-019-04979-7

8. Mohamed, A. A., \& Jan, Y.-K. (2019). Effect of Adding Proprioceptive Exercise to Balance Training In Older Adults with Diabetes: A Systematic Review. Current Diabetes Reviews, 15. https://doi.org/10.2174/1573399815666190712200147

9. Ferris, J. K., Inglis, J. T., Madden, K. M., \& Boyd, L. A. (2019). Brain and Body: A Review of Central Nervous System Contributions to Movement Impairments in Diabetes. Diabetes, 69(1), 3-11. https://doi.org/10.2337/db19-0321

10. Schwartz AV, Hillier TA, Sellmeyer DE, Resnick HE, Gregg E, Ensrud KE, et al. Older women with diabetes have higher risk of falls. A prospective study. Diabetes care. 2002; 25: 1749-1754.

11. Umpierre D, Ribeiro PA, Kramer CK, Leitao CB, Zucatti AT, Azevedo MJ, Gross JL, et al. Physical activity advice only or structured exercise training and association with HbA1c levels in type 2 diabetes: a systematic review and meta-analysis. JAMA. 2011; 305: 1790-1799.

12. Figueira FR, Umpierre D, Cureau FV et al. Association between physical activity advice only or structured exercise training with blood pressure levels in patients with type 2 diabetes: a systematic review and meta-analysis. Sports Medicine. 2014; 44: 1557-1572.

13. Cadore EL, Moneo ABB, Mensat MM, et al. Positive effects of resistance training in frail elderly patients with dementia after long-term physical restraint. Age. 2014; 35: 801-811.

14. Yamamoto R, Kinoshita T, Momoki T, Arai T, Okamura A, Hirao K, et al. Postural sway and diabetic peripheral neuropathy. Diabetes research and clinical practice. 2001; 52: 213-221.

15. Horak FB, Dickstein R, Peterka RJ. Diabetic neuropathy and surface sway-referencing disrupt somatosensory information for postural stability in stance. Somatosensory and motor research. 2002; 19:316-326.

16. Boucher P, Teasdle N, Courtemanche R, et al. Postural stability in diabetic polyneuropathy. Diabetes Care. 1995; 18: 638-645.

17. Simoneau GG, Ulbrecht JS, Derr JA, et al. Postural instability in patients with diabetic sensory neuropathy. Diabetes care. 1994; 17: 1411-1421.

18. Roman de Mettelinge T, Cambier D, Calders P, et al. Understanding the relationship between type 2 diabetes mellitus and falls in older adults: a prospective cohort study. PloS One. 2013; 8: e67055.

19. Ivers RQ, Cumming RG, Mitchell P, et al. Diabetes and risk of fracture: the Blue Mountains Eye Study. Diabetes Care. 2001; 24: 1198-1203.

20. Yau RK, Strotmeyer ES, Resnick HE, et al. Diabetes and risk of hospitalized fall injury among older adults. Diabetes Care. $2013 ; 36: 3985-3991$.

21. Napoli N, Strotmeyer ES, Ensrud KE, et al. Fracture risk in diabetic elderly men: the MrOS study. Diabetologia. 2014; 57: $2057-2065$.

22. Yamaguchi T, SugimotoT. Bone metabolism and fracture risk in type 2 diabetes mellitus. Journal of Endocrinology. 2011; 58: 613-624. 
23. Strotmeyer ES, Cauley JA, Schwartz AV, et al. Nontraumatic fracture risk with diabetes mellitus and impaired fasting glucose in older white and black adults: the health, aging and body composition study. Archives of Internal Medicine. 2005; 165: 1612-1617.

24. Pijpers E, Ferreira I, de Jongh RT, et al. Older individuals with diabetes have an increased risk of recurrent falls: analysis of potential mediating factors, the Longitudinal Ageing Study Amsterdam. Ageing. 2012; 41: 358-365.

25. Morrison S, Colberg SR, Parson HK, et al. Exercise improves gait, reaction time and postural stability in older adults with type 2 diabetes and neuropathy. Journal of Diabetes Complications. 2014; 28: 715-722.

26. Reid RD, Tulloch HE, Sigal RJ, et al. Effects of aerobic exercise, resistance exercise or both on patient-reported health status and well-being in type 2 diabetes mellitus: a randomised trial. Diabetologia.2010; 53: 632-640.

27. Kruse RL, Lemaster JW., Madsen RW. Fall and balance outcome after an intervention to promote leg strength, balance and walking in people with diabetic peripheral neuropathy: „feet first” randomized controlled trial. Physical Theraphy. 2010; 90: 1568-1579.

28. Allet L, Armand S, de Bia RA, et al. The gait and balance of patients with diabetes can be improved: a randomised controlled trial. Diabetologia. 2010; 53 : 458-466.

\section{Figures}
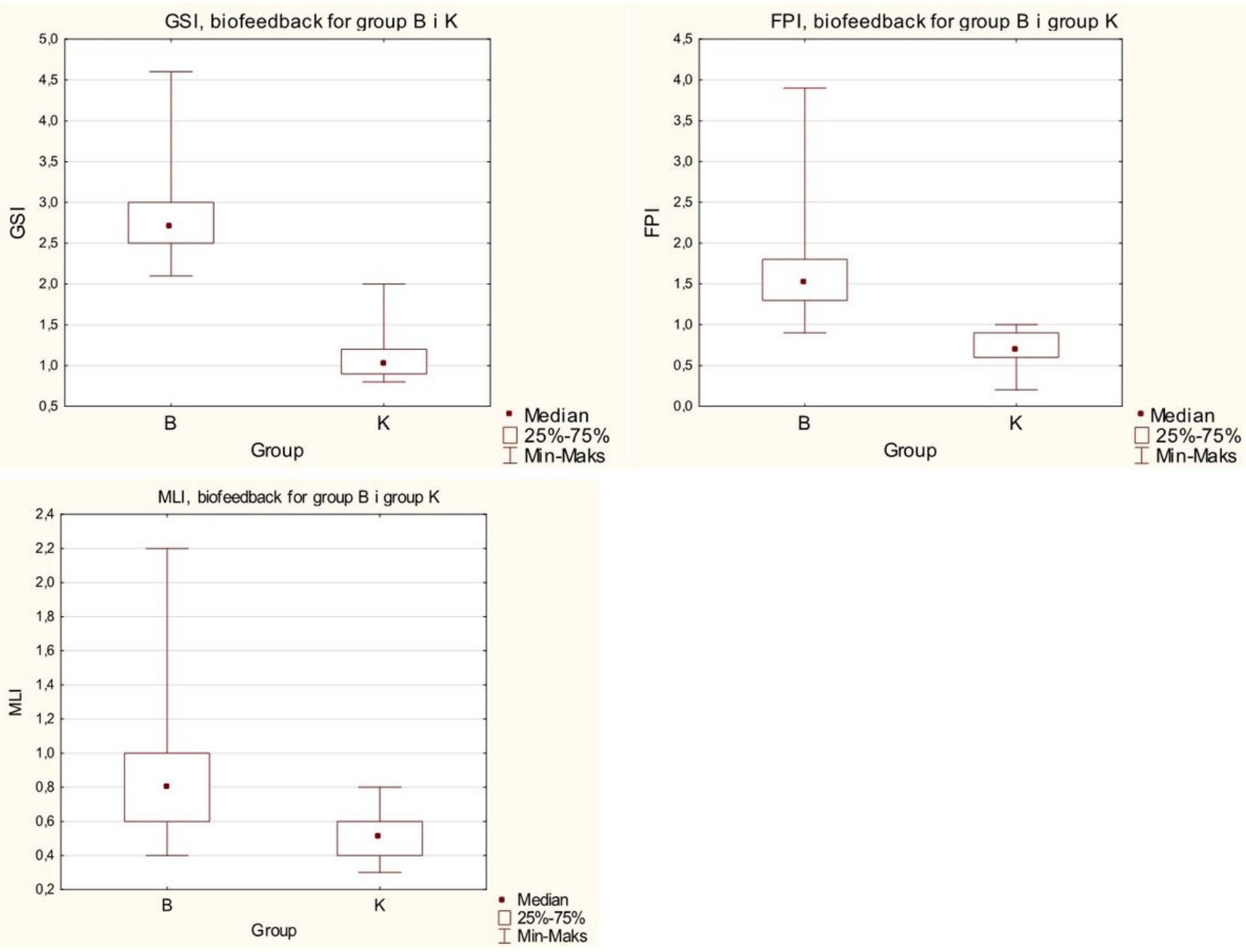

Figure 1

Differences in biofeedback posture test scores for GPI, FPI and MLI 
GPI, biofeedback Group B

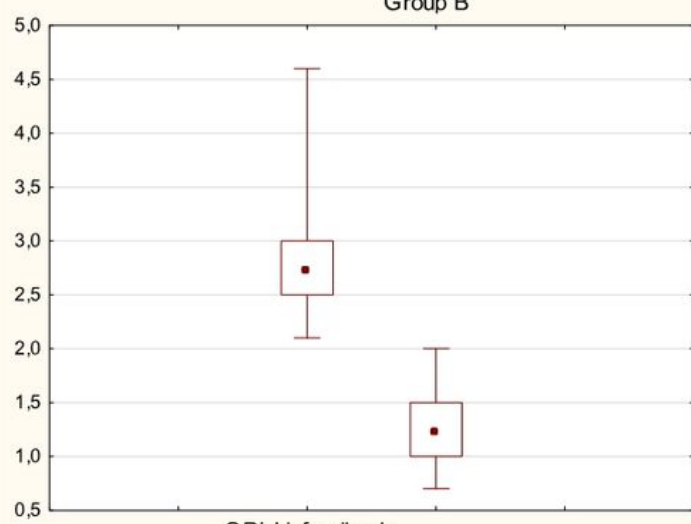

GPI biofeedback

GPI biofeedback after

MLI, biofeedback

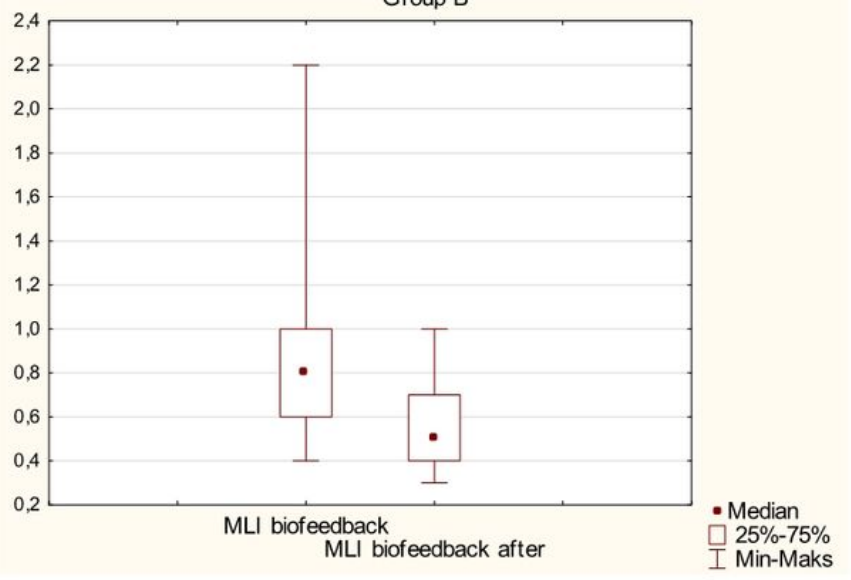

FPI, biofeedback Group B

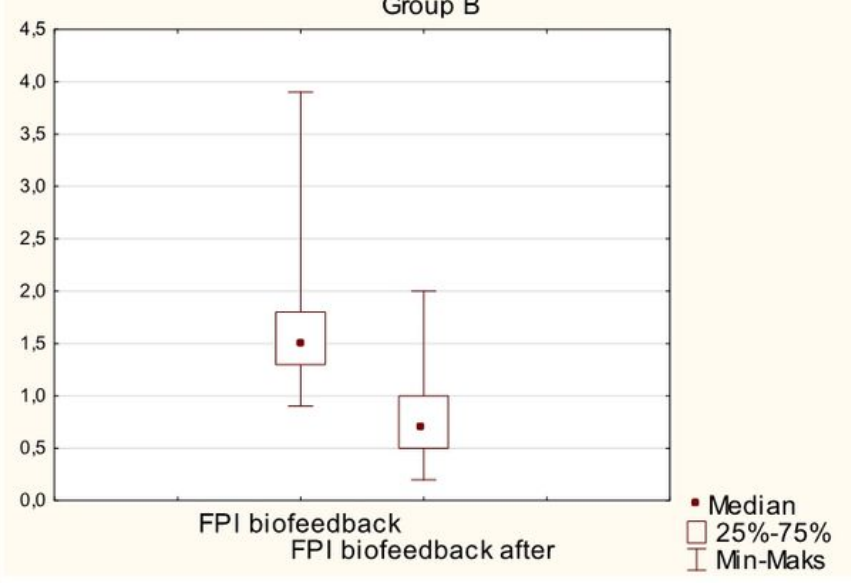

\section{Figure 2}

Results for the biofeedback posture test before and after training in group B 

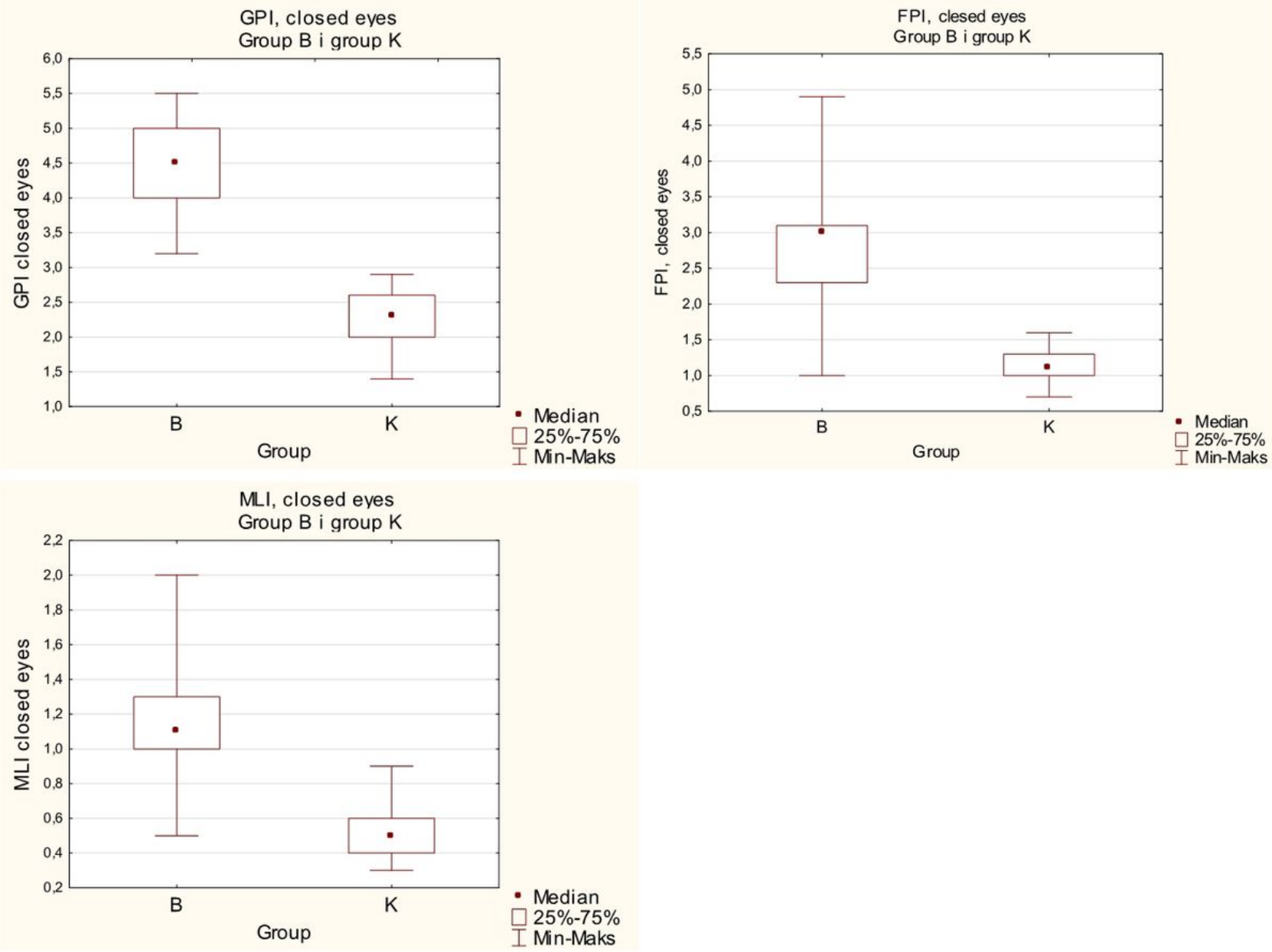

Figure 3

Analysis of results for GPI, FPI and MLI between group $\mathrm{K}$ and group B before training 

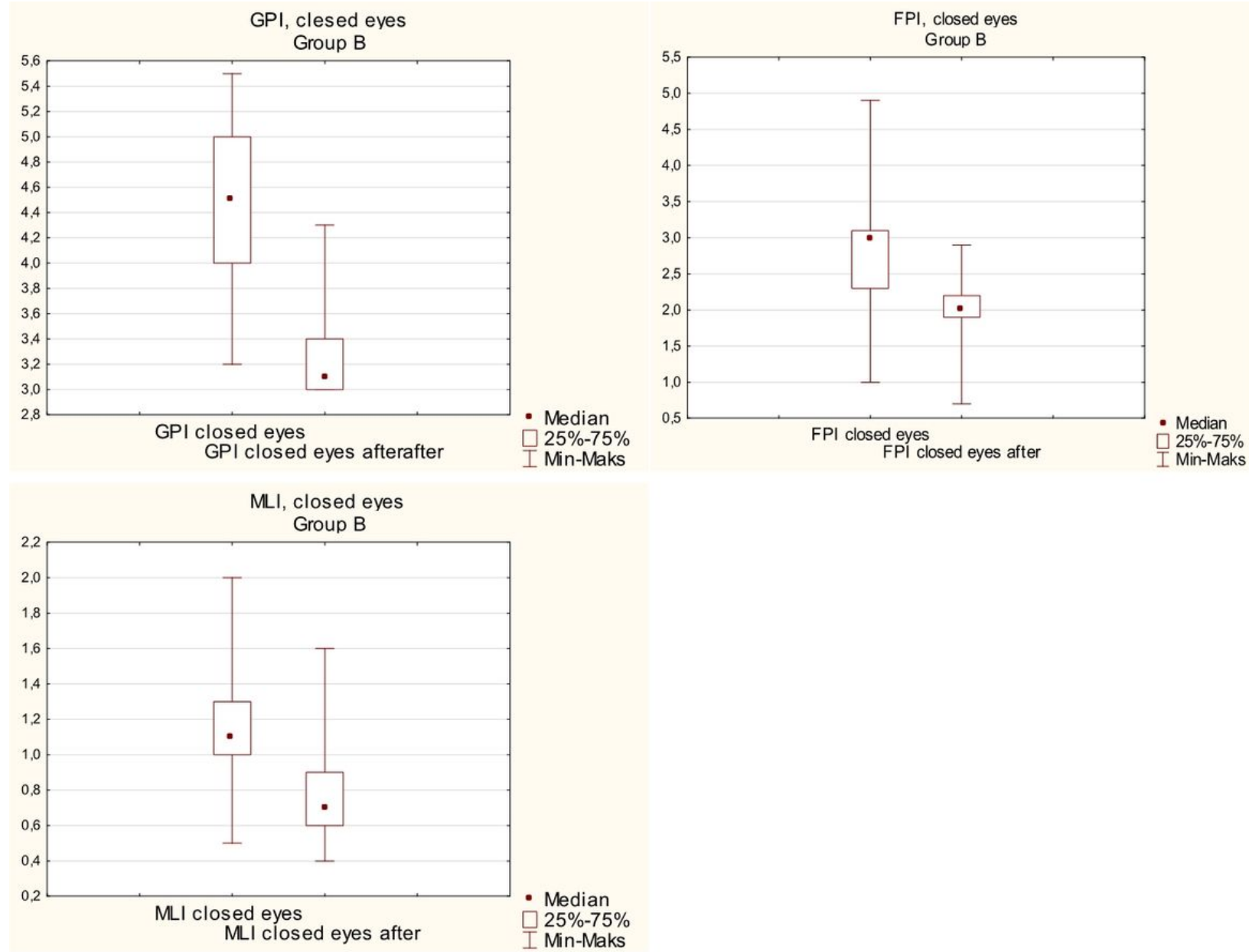

\section{Figure 4}

Analysis of postural stability test results with closed eyes before and after training session

Fall risk test (RF)

Group B i group K

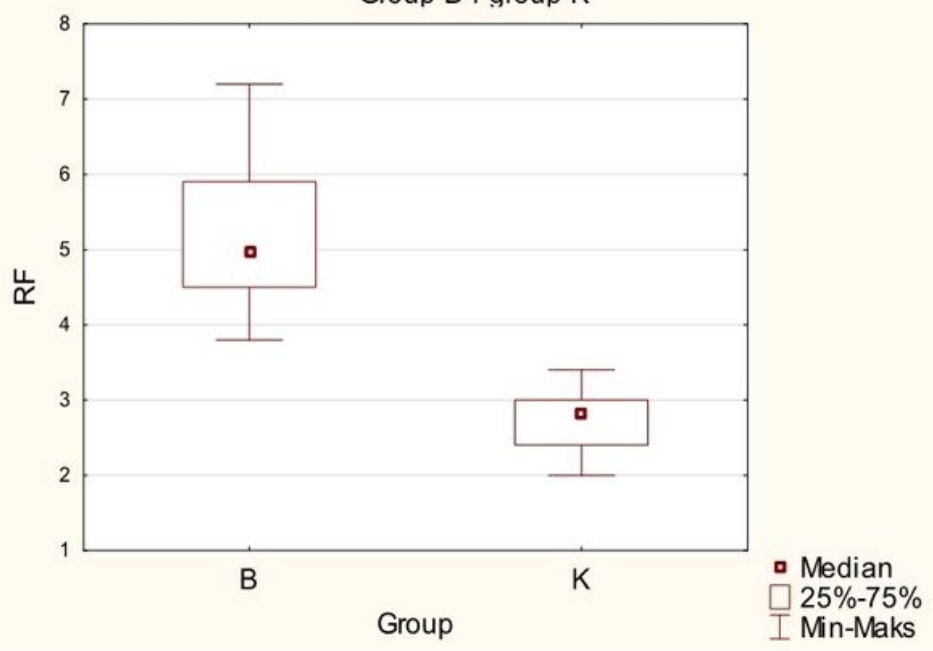

Risk fall test (RF)

Group B

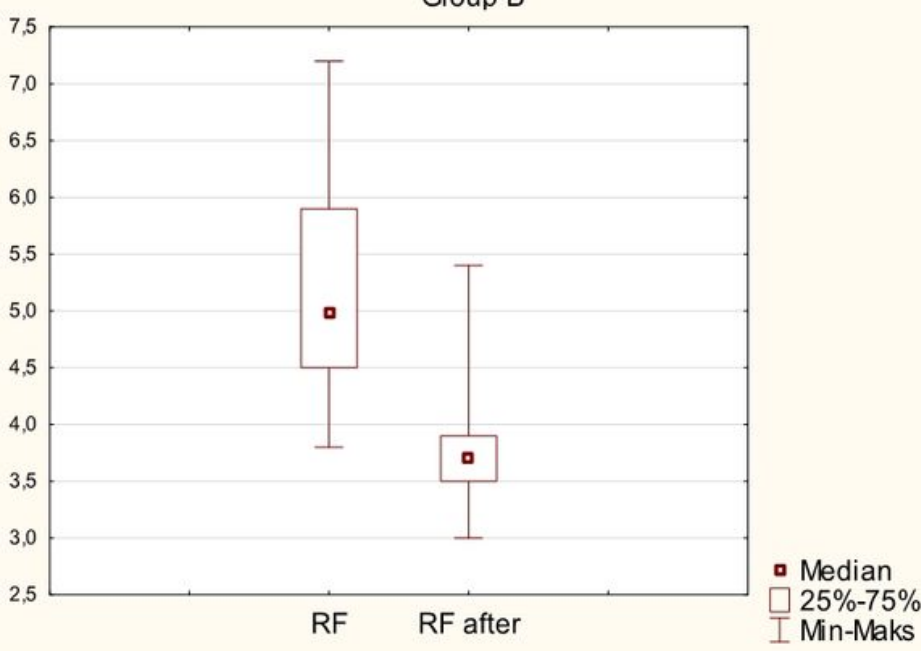

Figure 5

Analysis of the risk of falling in people with diabetes compared to healthy individuals 


\section{Supplementary Files}

This is a list of supplementary files associated with this preprint. Click to download.

- CONSORT2010Checklistdmd.doc 